\title{
PENAFSIRAN NILAI KETIDAKPASTIAN ANALISIS Fe, Ca, Zr, Ba, La, Ti DAN Ce DALAM CUPLIKAN SEDIMEN DENGAN METODA XRF
}

\author{
Sukirno, Agus Taftazani \\ Pusat Teknologi Akselerator dan Proses Bahan BATAN \\ Jl. Babarsari Kotak Pos 6101 ykbb, Yogyakarta 55281
}

Diterima 29 Desember 2009, diterima dalam bentuk perbaikan 18 Januari 2010, disetujui 19 Januari 2010

\begin{abstract}
ABSTRAK
PENAFSIRAN NILAI KETIDAKPASTIAN ANALISIS Fe, Ca, Zr, Ba, La, Ti DAN Ce DALAM CUPLIKAN SEDIMEN DENGAN METODA XRF. Telah dilakukan pengujian ketidakpastian untuk analisis $\mathrm{Fe}, \mathrm{Ca}, \mathrm{Zr}, \mathrm{Ba}, \mathrm{La}$, Ti dan $\mathrm{Ce}$ dalam cuplikan sedimen sungai Pancuran Wonosari. Nilai suatu hasil pengujian tidak akan bermakna tanpa disertai dengan perhitungan nilai ketidakpastian. Sebagai contoh telah disajikan perhitungan ketidakpastian analisis logam Ba dalam makalah ini. Tujuan penelitian ini adalah untuk memenuhi persyaratan akreditasi alat X-Ray Fluorescence (XRF) di laboratorium kimia analitik PTAPB - BATAN sesuai standar ISO/IEC 17025-2005. Hasil penafsiran ketidakpastian pengukuran pada analisis logam $\mathrm{Fe}, \mathrm{Zr}, \mathrm{Ba}, \mathrm{La}, \mathrm{Ce}, \mathrm{Ti}$ dan $\mathrm{Ca}$ menunjukkan bahwa, komponen ketidakpastian berasal dari: tahapan preparasi sampel dan standar/pembanding, kemurnian bahan, statistik pencacahan sampel dan standar, serta kedapatulangan. Hasil analisis kuantitatif diketahui bahwa logam yang terkandung dalam sedimen sungai Pancuran di Wonosari adalah $F e=7,290 \%, Z r=54,5 \mathrm{mg} / \mathrm{kg}, B a=1661,6 \mathrm{mg} / \mathrm{kg}$, $\mathrm{La}=22,9 \mathrm{mg} / \mathrm{kg}, \mathrm{Ce}=161,0 \mathrm{mg} / \mathrm{kg}, \mathrm{Ti}=3193,2$ dan $\mathrm{Ca}=7,816 \%$, sedangkan penafsiran ketidakpastian logam $\mathrm{Fe}$, $\mathrm{Zr}, \mathrm{Ba}, \mathrm{La}, \mathrm{Ce}$, Ti dan Ca berturut-turut adalah $\pm 0,60 \%, \pm 4,5 \mathrm{mg} / \mathrm{kg}, \pm 55 \mathrm{mg} / \mathrm{kg}, \pm 1,4 \mathrm{mg} / \mathrm{kg}, 12,0 \mathrm{mg} / \mathrm{kg}, \pm 208$ $\mathrm{mg} / \mathrm{kg}$ dan $\pm 0,61 \%$.
\end{abstract}

Kata kunci : Ketidakpastian, sedimen, XRF, ISO 17025-2005

\begin{abstract}
UNCERTAINTY ESTIMATION OF ANALYSIS OF Fe, Ca, Zr, Ba, La, Ti DAN Ce IN SEDIMENT SAMPLE USING XRF METHOD. An uncertainty of analysis of $\mathrm{Fe}, \mathrm{Ca}, \mathrm{Zr}, \mathrm{Ba}, \mathrm{La}, \mathrm{Ti}$ and $\mathrm{Ce}$ in river sediment of Pancuran Wonosari sample by XRF method has been done. The result value of testing is meaningless if it isn't completed without uncertainty value. The calculation of Ba metal have been presented for example. The aim of the research is to get accreditation certificate of X-Ray Fluorescence method on laboratory of analytical PTAPB - BATAN as well as ISO guide 17025-2005. The result of calculation uncertainty of $\mathrm{Fe}, \mathrm{Zr}, \mathrm{Ba}, \mathrm{La}, \mathrm{Ce}, \mathrm{Ti}$ and $\mathrm{Ca}$ analysis showed that the uncertainty components come from: preparation of sample and standard/comparator, purity of material, counting statistic (sample and standard) and repeatability. The results showed that metals in river sediment of Pancuran Wonosari were $F e=7.290 \%, Z r=54.5 \mathrm{mg} / \mathrm{kg}, \mathrm{Ba}=1661.6 \mathrm{mg} / \mathrm{kg}, \mathrm{La}=22.9 \mathrm{mg} / \mathrm{kg}, \mathrm{Ce}=161.0 \mathrm{mg} / \mathrm{kg}, \mathrm{Ti}=3193.2$ and $\mathrm{Ca}=7.816 \%$, and the result of uncertainty estimate of $\mathrm{Fe}, \mathrm{Zr}, \mathrm{Ba}, \mathrm{La}, \mathrm{Ce}, \mathrm{Ti}$ and Ca were $\pm 0.60 \%, \pm 4.5$ $\mathrm{mg} / \mathrm{kg}, \pm 55 \mathrm{mg} / \mathrm{kg}, \pm 1.4 \mathrm{mg} / \mathrm{kg}, 12.0 \mathrm{mg} / \mathrm{kg}, \pm 208 \mathrm{mg} / \mathrm{kg}$ and $\pm 0.61 \%$.
\end{abstract}

Keyword: Uncertainty, sediment, XRF, ISO 17025-2005

\section{PENDAHULUAN}

Dusat Teknologi Akselerator dan Proses Bahan (PTAPB) mempunyai alat X-Ray Fluorescence (XRF) di laboratorium kimia analitik (Radiokimia) PTAPB - BATAN yang baru tiba Agustus 2008. Alat XRF ini selain digunakan untuk penelitian analisis logam juga untuk kegiatan jasa analisis. Dalam rangka mendukung program penggunaan alat XRF di laboratorium yang memperoleh pengakuan formal atau sertifikat akreditasi diperlukan hasil uji yang valid dengan ralat atau ketidakpastian pengukuran sekecil mungkin. Salah satu hasil uji yang diperlukan dalam rangka memperoleh sertifikat akreditasi adalah ketidakpastian pengukuran, sehingga diperoleh pengakuan dari pengguna yang dituangkan dalam sertifikat mutu dari Komite Akreditasi Nasional (KAN). 
Program PTAPB dalam perluasan akreditasi labotorium perlu melakukan pengujian ketidakpastian terhadap suatu bahan dengan metoda XRF, agar diperoleh data yang memenuhi standar ISO/IEC 17025-2005, sehingga data yang dihasilkan dapat menunjang pengakuan keberadaan laboratorium bagi pengguna alat tersebut ${ }^{(1)}$. Untuk itu laboratorium pengujian harus juga mempunyai dan menerapkan prosedur untuk mengestimasi ketidakpastian pengukuran tersebut.

Analisis secara spektrometri pendar sinar $\mathrm{X}$ dapat digunakan secara kualitatif maupun kuantitatif. Analisis secara kualitatif meliputi pembacaan spektrum sinar $X$ dalam cuplikan, identifikasi puncak-puncak, hingga klasifikasi setiap unsur berdasarkan intensitas puncaknya. Analisis secara kualitatif mampu menganalisis semua unsur dengan nomor atom $\geq 15$ dalam satu cuplikan sekaligus ${ }^{(2,3)}$.

Sumber-sumber ketidakpastian dalam metode pendar sinar-X (X-Ray Fluorescence; XRF) dalam analisis seluruhnya dapat dibuat secara lengkap. Membuktikan bahwa XRF merupakan metoda mampu telusur, XRF biasanya dilakukan dengan metoda komparatif yang menggunakan standar logam murni yang disiapkan dari standar primer. Sumber-sumber ketidakpastian pengukuran dapat berasal dari setiap tahapan yang dikerjakan dalam menganalisis suatu logam dalam suatu sampel. Seperti dari proses preparasi sampel, pencacahan dan analisis. Mata rantai yang mempengaruhi perhitungan konsentrasi dengan metoda komparatif meliputi penimbangan dengan timbangan terkalibrasi dan tersertifikasi, konsentrasi, kemurnian standard dan pencacahan sampel.

Secara umum ketidakpastian pengukuran terdiri dari beberapa komponen yang dapat diklasifikasikan menurut metoda yang digunakan untuk menaksir nilai numeriknya: i) Tipe $A$, yang dievaluasi dengan analisis statistik dari rangkaian pengamatan, atau berdasarkan eksperimen (pengamatan ulang), ii) Tipe B yang dievaluasi dengan cara selain analisis statistik dari serangkaian pengamatan, atau berdasarkan informasi yang dapat dipercaya ${ }^{(4,5)}$.

\section{Evaluasi ketidakpastian baku tipe A:}

Bila dilakukan pengamatan kedua (ulang) dari n pengamatan berulang, maka dapat dihitung kembali nilai rata-ratanya yang kemungkinan terjadi sedikit perbedaan dengan nilai rata-rata yang pertama. Taksiran sebaran dari rata-rata populasi dapat dihitung dari simpangan baku (S) rata-rata eksperimental:

$$
\mu=S / \sqrt{ } n
$$

\section{Evaluasi ketidakpastian baku tipe $B$ :}

Untuk evaluasi ketidakpastian baku tipe $B$, dengan sumber ketidakpastian yang dilaporkan dalam sertifikat. Nilai ketidakpastian bakunya sama dengan ketidakpastian bentangan dibagi dengan faktor cakupan yang diberikan dalam sertifikat, bila tidak ada informasi faktor cakupan, maka dapat diambil 2 (dua) dengan tingkat kepercayaan $95 \%{ }^{(5)}$, untuk distribusi normal persamaan (2) dan distribusi rektangular persamaan (3) dan untuk distribusi trangular persamaan (4).

$$
\begin{aligned}
& \mu(x)=S / 2 \\
& \mu(x)=S / \sqrt{ } 3 \\
& \mu(x)=S / \sqrt{ } 6
\end{aligned}
$$

Agar mempunyai arti, pernyataan ketidakpastian harus mempunyai suatu tingkat kepercayaan. Oleh karena itu diperlukan pernyataan probabilitas bahwa nilai benarnya berada dalam rentang tersebut. Penetapan tingkat kepercayaan berdasar pada asumsi bahwa hasil pengukuran merupakan distribusi normal (Gauss). Dengan penetapan tingkat kepercayaan tersebut, diperoleh ketidakpastian diperluas ${ }^{(4)}$

Untuk mengetahui seberapa besar ketidakpastian pengukuran yang dilakukan dalam analisis bahan dengan metoda XRF, maka perlu dilakukan penaksiran nilai ketidakpastian hasil pengukuran pada analisis suatu sampel dengan metoda tersebut. Di sini akan dihitung seberapa besar sumbangan kesalahan dari tiap langkah berdasarkan percobaan, yang akhirnya dapat diketahui nilai ketidakpastian diperluas. Hal ini diperlukan karena suatu nilai pengujian tidak bermakna apabila tidak disertai dengan nilai ketidakpastian perhitungan. Sehingga hal yang sama perlu dilakukan untuk setiap analisis penentuan nilai suatu logam dalam suatu bahan. 
Tujuan penelitian ini adalah menentukan nilai ketidakpastian pengukuran logam $\mathrm{Fe}, \mathrm{Zr}$, Ba, La, Ce $\mathrm{Ca}$ dan Ti untuk memenuhi persyaratan ISO guide 17025-2005 yang telah diterapkan pada laboratorium kimia analitik Bidang Kimia dan Teknologi Proses Bahan.

\section{METODOLOGI}

\section{Alat}

Seperangkat spektrometer meter pendar sinar-X dengan menggunakan detektor $\mathrm{Si}(\mathrm{Li})$, timbangan analitik yang terkalibrasi, alat penjemur cuplikan dan wadah pencacahan.

\section{Bahan}

Cuplikan contoh uji sedimen, cuplikan standard reference material (SRM) with Buffalo river sediment 2704, sumber standar kalibrasi Cd, Sr, Sm, Ca dan Ti. Sumber eksitasi Am-241 dan Fe-55.

\section{Preparasi contoh uji}

Cuplikan sedimen diambil dari sungai Pancuran di Wonosari, Kabupaten Gunung Kidul Propinsi DIY, sedimen dibersihkan dari kotoran dan dikeringkan, kemudian digerus sampai halus lolos 100 mesh dan dihomogenkan dan dimasukkan ke wadah yang berlabel. Cuplikan/contoh uji sedimen dan standar SRM ditimbang seberat 4 gram dalam wadah pencacahan.

\section{Penimbangan cuplikan}

Timbangan elektronik semi-mikro tipe/ Model AP 2500 buatan OHAOUS Corp USA, Nomor Serifikat: S.080018/VII/IIS/05 dengan kapasitas maksimal $210 \mathrm{~g}$ dan resolusi $0.01 \mathrm{mg}$, ketidakpastian timbangan tersebut adalah $\mu= \pm 0,52 \mathrm{mg}$, ripitabilitas penimbangan dilakukan 10 kali ulang didapatkan standar deviasi ripitabilitas $0,03 \mathrm{mg}^{(6)}$. Sampel sedimen sungai Pancuran dan cuplikan standar SRM masing-masing ditimbang $4 \mathrm{~g}$ (4000 $\mathrm{mg}$ ) dalam wadah pencacahan.

\section{Pencacahan dan penentuan konsentrasi logam}

Pencacahan dilakukan selama 600 detik untuk contoh uji sedimen dan standar SRM. Untuk pencacahan logam $\mathrm{Fe}, \mathrm{Zr}, \mathrm{Ba}$, La dan Ce menggunakan sumber eksitasi Am-241 dan untuk menentukan logam $\mathrm{Ti}$, dan $\mathrm{Ca}$ menggunakan sumber eksitasi Fe-55. Dalam penelitian ini untuk menghitung konsentrasi cuplikan digunakan metoda relatif atau komparatif, oleh karena itu cuplikan standar telah mengandung logam yang akan ditentukan, dengan jumlah dan komposisinya telah diketahui dengan pasti.

Rumus penentuan konsentrasi logam dalam cuplikan contoh uji sedimen:

$$
\text { Konsentrasi, } \mathrm{Cc}=\frac{\mathrm{Ic}}{\mathrm{Is}} \mathrm{Cs}
$$

dengan : Cc : konsentrasi logam yang diperhatikan dalam contoh uji

Cs : konsentrasi logam dalam standar (SRM)

Ic : Intensitas logam yang diperhatikan dalam contoh uji

Is : Intensitas logam yang dalam standar (SRM)

\section{Pengaruh ketidakpastian timbangan}

Pengaruh ketidakpastian pada timbangan, kalibrasi timbangan, kemampuan pembacaan skala (resolusi) dan ripitabilitas (pengulangan pengukuran). Perhitungan ketidakpastian gabungan penimbangan $\left(\mu_{\mathrm{c}}\right)$ untuk sampel dan standar, dijumlahkan, dikuadratkan dan ditarik akar pangkat dua dari jumlah.

\section{Pengaruh ketidakpastian pada penimbangan sampel dan standar}

Pengaruh perhitungan ketidakpastian pada penimbangan sampel dan standar dan ketidakpastian standar SRM pada setifikat, akan didapatkan ketidakpastian bakunya. Menentukan ketidakpastian baku dari statistik pencacahan dan standar deviasi untuk sampel dan standar yang digunakan. Dilakukan perhitungan ketidakpastian gabungan dan ketidakpastian diperluas, perhitungan ketidakpastian dapat dilihat pada pembahasan dan diambil contoh untuk logam Ba. 


\section{HASIL DAN PEMBAHASAN}

\section{Faktor yang berpengaruh pada ketidakpastian}

Untuk menentukan ketidakpastian terdapat beberapa langkah, yaitu :

a. Penyusunan suatu model dari langkah pekerjaan dan menentukan formula yang digunakan dalam perhitungan hasil pengukuran.

b. Faktor yang berkontribusi dalam ketidakpastian dalam formula tersebut.

c. Inventarisasi semua faktor yang dapat memberikan kontribusi kesalahan terhadap hasil akhir.

Identifikasi dapat dilakukan dengan membuat cause and effect diagram (fish-bone diagram). Faktor-faktor yang berpengaruh pada ketidakpastian terlihat pada Gambar 1.

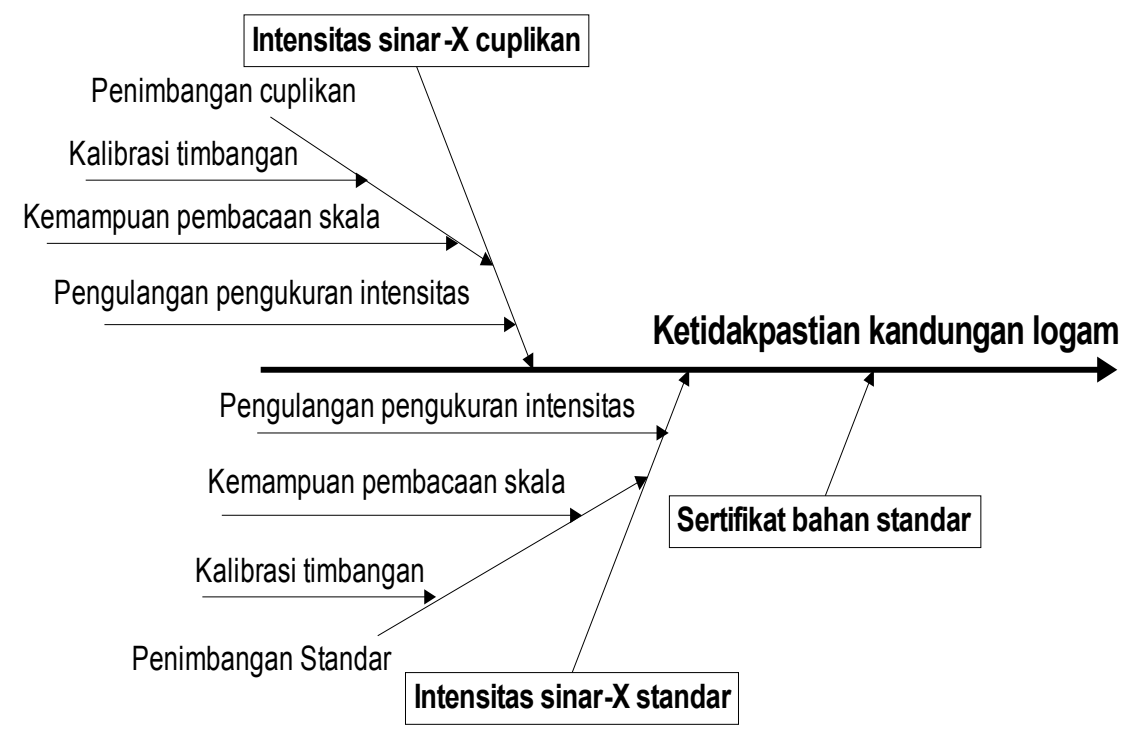

Gambar 1. Fish-bone faktor-faktor yang berpengaruh pada ketidakpastian dengan metoda komparatif intensitas sinar-X karakteristik

\section{Perhitungan intensitas logam/intensitas Compton untuk standard dan contoh uji sedimen}

Pada spektrum pendar sinar- $X$ dari analisis sedimen cuplikan standard reference material (SRM) with Buffalo river sediment 2704 dan contoh uji sedimen, diidentifikasi pada puncak-puncak sinar-X karakteristik pada energi Fe (6,403 keV); Zr (15,774 keV); Ba (32,191 keV); La (33,440 keV) dan Ce (34,717 keV) menggunakan sumber eksitasi Am-241 sedangkan $\mathrm{Ca}(3,691 \mathrm{keV})$ dan Ti (4,510 keV) menggunakan sumber eksitasi Fe- 55 .

Hasil perhitungan masing-masing intensitas logam/intensitas Compton untuk standar disajikan pada Tabel 1, dengan pengulangan cacah 10 kali. Hasil rerata dan standar deviasi diperlukan untuk menghitung salah satu faktor kesalahan dalam perhitungan ketidakpastian.

Tabel 1. Hasil hitung masing-masing intensitas logam/intensitas Compton untuk standar (hasil rerata) dan standar deviasi (SD)

\begin{tabular}{|c|c|c|c|c|c|c|c|}
\hline \multirow{2}{*}{$\begin{array}{c}\text { Nomor } \\
\text { SRM }\end{array}$} & \multicolumn{7}{|c|}{ Intensitas logam /Intensitas Compton Standar } \\
\cline { 2 - 8 } & Fe/C & Zr/C & Ba/C & La/C & Ce/C & Ti/C & Ca/C \\
\hline 1 & 0,03537 & 0,01309 & 0,080487 & 0,003515 & 0,01195 & 0,24185 & 1,53533 \\
\hline 2 & 0,03263 & 0,01189 & 0,079187 & 0,003719 & 0,01137 & 0,33154 & 1,78706 \\
\hline 3 & 0,03644 & 0,0162 & 0,078841 & 0,004196 & 0,00910 & 0,34462 & 1,86154 \\
\hline 4 & 0,03707 & 0,01428 & 0,079769 & 0,003615 & 0,00997 & 0,39514 & 1,68693 \\
\hline 5 & 0,03319 & 0,01469 & 0,082384 & 0,003881 & 0,00579 & 0,28421 & 1,73158 \\
\hline 6 & 0,03524 & 0,01436 & 0,07635 & 0,003788 & 0,00762 & 0,32857 & 1,79714 \\
\hline
\end{tabular}


Penafsiran Nilai Ketidakpastian Analisis Fe, Ca, Zr, Ba, La, Ti dan Ce Dalam Cuplikan Sedimen Dengan Metoda XRF (Sukirno, dkk.)

\begin{tabular}{|c|c|c|c|c|c|c|c|}
\hline \multirow{2}{*}{$\begin{array}{c}\text { Nomor } \\
\text { SRM }\end{array}$} & \multicolumn{7}{|c|}{ Intensitas logam /Intensitas Compton Standar } \\
\cline { 2 - 8 } & Fe/C & Zr/C & Ba/C & La/C & Ce/C & Ti/C & Ca/C \\
\hline 7 & 0,03152 & 0,0134 & 0,07623 & 0,004123 & 0,0105 & 0,3118 & 1,61517 \\
\hline 8 & 0,03683 & 0,01425 & 0,078582 & 0,00376 & 0,01016 & 0,27746 & 1,70809 \\
\hline 9 & 0,03411 & 0,01316 & 0,075796 & 0,004218 & 0,01160 & 0,30959 & 1,63836 \\
\hline 10 & 0,03268 & 0,01547 & 0,079516 & 0,003633 & 0,01091 & 0,27654 & 1,72626 \\
\hline Rerata & 0,03451 & 0,01407 & 0,078714 & 0,003845 & 0,00990 & 0,31013 & 1,70875 \\
\hline SD $( \pm)$ & 0,00135 & 0,00119 & 0,000486 & 0,000059 & 0,00052 & 0,01735 & 0,09547 \\
\hline
\end{tabular}

Hasil perhitungan masing-masing intensitas logam/intensitas Compton untuk contoh uji sedimen sungai Pancuran di Wonosari disajikan pada Tabel 2, dengan pengulangan cacah 7 kali. Pada Tabel 2 dapat dilihat hasil rerata intensitas logam/intensitas Compton dan standar deviasi (SD) yang mempunyai nilai berbeda untuk setiap logam.

Tabel.2 : Hasil hitung intensitas logam/intensitas Compton dan rerata serta standar deviasi (SD) untuk cuplikan contoh uji sedimen Pancuran

\begin{tabular}{|c|c|c|c|c|c|c|c|}
\hline \multirow{2}{*}{ I/C } & \multicolumn{7}{|c|}{ Intensitas logam/ intensitas Compton contoh uji sedimen } \\
\hline & $\mathrm{IFe} / \mathrm{C}$ & $\mathrm{Zr} / \mathrm{C}$ & $\mathrm{Ba} / \mathrm{C}$ & $\mathrm{La} / \mathrm{C}$ & $\mathrm{Ce} / \mathrm{C}$ & $\mathrm{Ti} / \mathrm{C}$ & $\mathrm{Ca} / \mathrm{C}$ \\
\hline Pancuran & 0,06259 & 0,00225 & 0,30739 & 0,00312 & 0,02517 & 0,25201 & 5,4182 \\
\hline & 0,06657 & 0,00255 & 0,30919 & 0,00323 & 0,02597 & 0,23262 & 5,2406 \\
\hline & 0,06098 & 0,00180 & 0,30220 & 0,00328 & 0,02188 & 0,09827 & 5,7369 \\
\hline & 0,06259 & 0,00225 & 0,31307 & 0,00350 & 0,02233 & 0,25201 & 5,3646 \\
\hline & 0,06464 & 0,00236 & 0,30531 & 0,00304 & 0,02500 & 0,20588 & 5,1871 \\
\hline & 0,06289 & 0,00204 & 0,30029 & 0,00309 & 0,02379 & 0,24277 & 5,6502 \\
\hline & 0,06336 & 0,00221 & 0,30620 & 0,00321 & 0,02370 & 0,2333 & 5,3943 \\
\hline Rerata & 0,06337 & 0,00222 & 0,30624 & 0,00321 & 0,02398 & 0,2167 & 5,4274 \\
\hline $\mathrm{SD}( \pm)$ & 0,00040 & 1,68E-05 & 0,00057 & 0,00004 & 0,00074 & 0,00935 & 0,0119 \\
\hline
\end{tabular}

\section{Perhitungan ketidakpastian untuk logam Ba dalam contoh uji sedimen}

Perhitungan ketidakpastian menentukan konsentrasi untuk logam Ba dalam contoh uji sedimen dengan metoda komparatif menggunakan standar pembanding SRM, disajikan pada Tabel $3-5$ di bawah ini. Preparasi sampel dan standar, sumber ketidakpastian pada tahap preparasi sampel dan standar diantaranya berasal dari penimbangan dan kemurnian standar. Komponen ketidakpastian dari penimbangan mengambil contoh untuk logam Ba dalam sampel sedimen.

Sumber ketidakpastian pada tahap preparasi sampel dan standar diantaranya berasal dari penimbangan dan kemurnian standar. Komponen ketidakpastian dari timbangan yang digunakan adalah timbangan elektronik semi-mikro tipe/Model AP 2500 buatan OHAOUS Corp USA, Nomor Serifikat: S.08-0018/VII/IIS/05 dengan kapasitas maksimal $210 \mathrm{~g}$ dan resolusi $0.01 \mathrm{mg}$. Pada sertifikat kalibrasi timbangan yang digunakan tertera ketidakpastian timbangan tersebut adalah $\mu= \pm 0,52 \mathrm{mg}^{(6)}$. Dengan faktor cukupan adalah 2, maka ketidakpastian baku $\left(\mu_{\mathrm{bt}}\right)$ adalah $0,52 / 2=0,26 \mathrm{mg}$. Resolusi timbangan menggunakan 5 digit maka pada pembacaan timbangan adalah $0,01 \mathrm{mg}$, maka ketidakpastian baku $\left(\mu_{\mathrm{br}}\right)$ menggunakan persamaan $(3)$ dan faktor cakupan 2 (ketidakpastian tipe B) adalah 0,01/2/ $\sqrt{3}=0,002887 \mathrm{mg}$. Ripitabilitas penimbangan dilakukan 10 kali pengulangan didapatkan standar deviasi ripitabilitas $0,03 \mathrm{mg}$, maka ketidakpastian baku $\left(\mu_{\mathrm{bR}}\right)$ menggunakan persamaan (1) (ketidakpastian tipe A) adalah $0,03 / \sqrt{10}=0.009483 \mathrm{mg}$. Ketidakpastian gabungan dari penimbangan cuplikan yang terdiri dari ketiga komponen yang telah dihitung diatas adalah 0,260189 $\mathrm{mg}$, dapat dilihat pada Tabel 3. 
Tabel 3. Ketidakpastian pada pengaruh timbangan dalam sampel sedimen metoda komparatif

\begin{tabular}{|l|c|c|c|}
\hline \multicolumn{1}{|c|}{ Kuantitas } & Ketidakpastian & $\boldsymbol{\mu}(\mathbf{m g})$ & Tipe \\
\hline Kalibrasi timbangan & 0,52 & $0,52 / 2=0,26$ & $\mathrm{~B}$ \\
\hline Resolusi & 0,01 & $0,01 / 2 / \sqrt{ } 3=0.00288675$ & $\mathrm{~B}$ \\
\hline Ripitabilitas & 0,03 & $0,03 / \sqrt{10}=0.009483$ & $\mathrm{~A}$ \\
\hline Pengaruh ketidakpastian penimbangan terhadap intensitas & {$\left[(0,26)^{2}+(0,00289)^{2}+(0,00948)^{2}\right]^{0,5}=0,260189$} & \\
\hline
\end{tabular}

Pada perhitungan konsentrasi dan ketidakpastian diambil logam Ba dalam contoh uji sedimen sungai Pancuran di Wonosari, Konsentrasi Ba dalam sertifikat adalah $432 \pm 13 \mathrm{mg} / \mathrm{kg}^{(7)}$ yang merupakan standar primer yang digunakan sebagai pembanding. Selanjutnya ketidakpastian gabungan faktor-faktor tersebut hanya terbatas pada statistik pencacahan dengan menggunakan metoda komparatif. Dari Tabel 1 hasil analisis pengukuran standar menghasilkan intensitas Ba/intensitas Compton rerata dengan nilai 0,078714 dan standar deviasi dengan nilai 0,000486 dengan 10 kali pengulangan. Pengukuran cuplikan contoh uji, intensitas Ba/intensitas Compton (I-Ba/C) rerata dari Tabel 2 dengan nilai 0.306246 dengan standar deviasi (SD) dengan nilai \pm 0.000571 dengan 7 kali pengulangan.

Tabel 4. Ketidakpastian dalam analisis logam Ba dalam standar dan sampel metoda komparatif

\begin{tabular}{|l|c|}
\hline \multicolumn{1}{|c|}{ Kuantitas } & Ketidakpastian baku \\
\hline Preparasi sampel $4000 \mathrm{mg}=0,260189 / 400^{*} 100 \%=0,6505$ & $0,6505 \%$ \\
\hline Preparasi standar 4000 $\mathrm{mg}=0,079845 / 400^{*} 100 \%$ & $0,6505 \%$ \\
\hline $\begin{array}{l}\text { Standar SRM }=423 \mathrm{mg} / \mathrm{kg} \text { dan ketidak pastian }=13 \\
=(13 / 423)^{*} 100 \%=3,07328 \% / 2=1,5366 \%\end{array}$ & $1,5366 \%$ \\
\hline $\begin{array}{l}\text { Statistik pencahan sampel } 0,30624 \text { dan setandar diviasi }=0,000571 \\
=(0,000571 / 0,30624)^{*} 100 \%=0,18645 \%\end{array}$ & $0,18645 \%$ \\
\hline $\begin{array}{l}\text { Statistik pencahan standar } 0.078714 \text { dan standar deviasi }=0,000487 \\
=(0,000487 / 0,01426)^{*} 100 \%=0,617425 \%\end{array}$ & $0,6174 \%$ \\
\hline $\begin{array}{l}\text { Ketidakpastian gabungan } \\
=\left[(0,6505)^{2}+(0,6505)^{2}+(1,5366)^{2}+(0,1864)^{2}+(0,6174)^{2}\right]^{0,5}=1,6689\end{array}$ & $1,669 \%$ \\
\hline
\end{tabular}

Pada Tabel 4 disajikan hasil ketidakpastian pengukuran logam Ba dari saat penimbangan sampai hasil pencacahan contoh uji logam Ba dalam sedimen. Untuk memudahkan penyerderhanaan keseragaman yang lebih jelas satuan ketidakpastian dibuat dalam prosentase (\%). Ketidakpastian preparasi sampel dan standar masing-masing penimbangan dengan berat $4000 \mathrm{mg}$, menghasilkan ketidakpastian baku dengan nilai 0,6505 \%. Statistik hasil pencacahan standar dan contoh uji sedimen menghasilkan ketidakpastian baku masing-masing sebesar 0,61742 \% dan 0,18645 \%. Ketidakpastian gabungan pada penimbangan cuplikan contoh uji dan standar untuk logam Ba mempunyai nilai 1,669 \%. Untuk logam lainnya yang terkandung dalam contoh uji sedimen Pancuran dapat diketahui nilai ketidakpastian dengan mengetahui data yang diperlukan seperti penentuan ketidakpastian logam Ba.

\section{Pengukuran mampu telusur}

Untuk memperoleh metoda analisis yang mampu telusur sesuai standar ISO-17025 harus mempunyai metrologi tinggi dimana analisis dapat secara lengkap menulis data dan dapat dimengerti. Dengan demikian ketidakpastian dapat secara lengkap ditulis sesuai standar internasional.

Ketidakpastian kandungan logam gabungan diperluas pada Tabel 5 menghasilkan konsentrasi Ba sebesar $1661,6 \mathrm{mg} / \mathrm{kg}$ dan ketidakpastian diperluas dengan nilai $54,8 \mathrm{mg} / \mathrm{kg}$ merupakan rentang nilai yang dinyatakan perkiraan nilai penelitian/pengujian berada, sehingga konsentrasi logam Ba dalam contoh uji sedimen nilainya terletak diantara 1661,6 $\pm 54,8 \mathrm{mg} / \mathrm{kg}$. Untuk konsentrasi atau kadar logam lainnya yang terkandung dalam contoh uji sedimen Pancuran dapat diketahui konsentrasi dengan mengetahui data yang diperlukan seperti penentuan logam Ba yang disajikan pada Tabel 5 . Hasil keseluruhannya dapat dilihat pada Tabel 6 :

Tabel 5. Hasil hitung nilai analisis logam Ba dengan hasil ketidakpastian 
Penafsiran Nilai Ketidakpastian Analisis Fe, Ca, Zr, Ba, La, Ti dan Ce Dalam Cuplikan Sedimen Dengan Metoda XRF (Sukirno, dkk.)

\begin{tabular}{|l|c|}
\hline \multicolumn{1}{|c|}{ Kuantitas } & Nilai \\
\hline Tingkat kepercayaan $95 \%$ & faktor cakupan $=2$ \\
\hline Ketidakpastian diperluas $=1,669 * 2=3,334 \%$ & $3,334 \%$ \\
\hline Nilai analisis $=0,30624 / 0,01426^{*} 423$ & $1661,6 \mathrm{mg} / \mathrm{kg}$ \\
\hline Ketidakpastian $=1661,6 * 3,334 \%=54,868$ & $54,87 \mathrm{mg} / \mathrm{kg}$ \\
\hline Konsentrasi Ba dalam contoh uji sedimen & $1661,6 \pm 54,8 \mathrm{mg} / \mathrm{kg}$ \\
\hline
\end{tabular}

Tabel 6. Hasil perhitungan konsentrasi dan ketidakpastian logam dalam sedimen Pancuran Wonosari

\begin{tabular}{|c|c|c|c|c|}
\hline Logam & Konsentrasi rerata & Ketidakpastian" $\boldsymbol{\mu}^{\prime}$ & Konsentrasi & Relatif deviasi \\
\hline $\mathrm{Fe}$ & $7,290 \%$ & 0,60 & $7,290 \pm 0,60 \%$ & $8,2 \%$ \\
\hline $\mathrm{Zr}$ & $54,5 \mathrm{mg} / \mathrm{kg}$ & 4,5 & $54,5 \pm 4,5 \mathrm{mg} / \mathrm{kg}$ & $8,2 \%$ \\
\hline $\mathrm{Ba}$ & $1645,7 \mathrm{mg} / \mathrm{kg}$ & 54,8 & $1661,6 \pm 54,8 \mathrm{mg} / \mathrm{kg}$ & $3,2 \%$ \\
\hline $\mathrm{La}$ & $22,9 \mathrm{mg} / \mathrm{kg}$ & 1,4 & $22,9 \pm 1,4 \mathrm{mg} / \mathrm{kg}$ & $6,1 \%$ \\
\hline $\mathrm{Ce}$ & $161,0 \mathrm{mg} / \mathrm{kg}$ & 12,0 & $161,0 \pm 12,0 \mathrm{mg} / \mathrm{kg}$ & $7,4 \%$ \\
\hline $\mathrm{Ti}$ & $3193,2 \mathrm{mg} / \mathrm{kg}$ & 308 & $3193,2 \pm 208 \mathrm{mg} / \mathrm{kg}$ & $6,5 \%$ \\
\hline $\mathrm{Ca}$ & $7,816 \%$ & 0,61 & $7,816 \pm 0,61 \%$ & $7,8 \%$ \\
\hline
\end{tabular}

Hasil penafsiran nilai ketidakpastian perhitungan pada analisis $\mathrm{Fe}, \mathrm{Ca}, \mathrm{Ti}, \mathrm{Zr}, \mathrm{Ba}$, La dan $\mathrm{Ce}$ yang terkandung dalam sedimen sungai ditunjukkan pada Tabel 6. Dari tabel tersebut terlihat bahwa nilai konsentrasi, nilai ketidakpastian dan relatif deviasi. Dimana dapat diketahui komponen-komponen dalam pelaksanaan analisis yang memberikan sumbangan nilai ketidakpastian perhitungan terhadap nilai hasil analisis, jenis atau tipe ketidakpastian baku. Sumber ketidakpastian pada analisis logam $\mathrm{Fe}, \mathrm{Zr}, \mathrm{Ba}, \mathrm{La}, \mathrm{Ce}, \mathrm{Ti}$ dan $\mathrm{Ca}$ dalam cuplikan contoh uji sedimen Pancuran Wonosari dapat berasal dari tahapan preparasi sampel, kemurnian standard dan pencacahan.

Dari perhitungan tersebut besar hasil analisis sedimen sungai Pancuran yang dianalisis dengan metoda komparatif intensitas karakteristik memberikan hasil analisis yang tepat dengan relatif deviasi yaitu perbandingan antara ketidakpastian logam terhadap konsentrasi rerata logamnya berkisar antara $(3-8) \%$ dan rentang ketidakpastian relatif lebih kecil dari $10 \%$. Nilai relatif deviasi juga menyatakan mutu hasil pengukuran atau pengujian, semakin kecil nilai relatif deviasi maka semakin baik hasil penelitian atau pengujian. Dengan melihat hasil estimasi ketidakpastian dan relatif deviasi hasil pengukuran tersebut maka metoda XRF untuk menganalisis logam $\mathrm{Fe}, \mathrm{Zr}, \mathrm{Ba}$, La, $\mathrm{Ce}$, Ti dan $\mathrm{Ca}$ yang terkandung dalam contoh uji sedimen cukup andal, dapat dipertanggungjawabkan dan valid.

Pada penyajian Tabel 6 terlihat bahwa yang mempunyai konsentrasi di atas 1\% adalah logam Fe dan Ca, logam ini merupakan kelompok logam mayor, yang paling dominan dalam sedimen. Konsentrasi Fe dalam sedimen dengan konsentrasi 7,290 \pm 0,60 \% dan $\mathrm{Ca} 7,816 \pm 0,61 \%$, hal ini disebabkan Fe dan Ca merupakan salah satu komponen utama dalam sedimen, khususnya $\mathrm{Ca}$ tanah sekitar sungai banyak mengandung kapur. Untuk logam $\mathrm{Zr}$, Ba, La, Ce, dan Ti merupakan kelompok logam minor yaitu yang mepunyai konsentrasi di bawah $1 \%$ atau $10.000 \mathrm{mg} / \mathrm{kg}^{(8,9)}$.

\section{KESIMPULAN}

1. Sumber ketidakpastian pada analisis logam $\mathrm{Fe}, \mathrm{Zr}, \mathrm{Ba}, \mathrm{La}, \mathrm{Ce}$, Ti dan Ca dalam cuplikan contoh uji sedimen Pancuran Wonosari dapat berasal dari tahapan preparasi sampel, kemurnian standard dan pencacahan.

2. Untuk mengetahui nilai benar suatu hasil pengujian berada, maka perlu dilakukan kuantifikasi nilai ketidakpastiannya. Hal ini perlu dilakukan untuk setiap logam yang akan dianalisis, karena nilai suatu hasil pengujian tidak ada maknanya tanpa disertai nilai-nilai ketidakpastiannya.

3. Hasil analisis sedimen sungai Pancuran yang dianalisis dengan metoda komparatif intensitas karakteristik memberikan hasil analisis yang tepat dengan relatif deviasi berkisar $(3-8) \%$ dan rentang ketidakpastian relatif lebih kecil dari 10\%. Dengan melihat hasil relatif deviasi hasil pengukuran tersebut, maka metoda XRF cukup andal, dapat dipertanggungjawabkan dan valid, untuk analisis logam dalam cuplikan. 


\section{DAFTAR PUSTAKA}

1. BSN., Persyaratan Umum Kompetensi Laboratorium Pengujian Kalibrasi, ISO/IEC 17025, edisi kedua, Jakarta (2005).

2. EUGENE.B.P., Introduction to X-Ray Spectrometry Analysis, Plenum Press, New York (1978).

3. DIXIT.R.M. AND DESHPANDE S.S., 1985, "X-Ray Fluorescence Determination of Pr, Nd, Gd, Tb, Dy and Y In High Purity Europium Oxide", Bhabha Atomic Research Centre, Bombay India (1985).

4. YUSTINA TRI HANDAYANI., Ketidakpastian pada Analisis Aktivasi Neutron Dengan Metoda Ko. Pusdiklat BATAN, Jakarta (2006).

5. SAMIN. Cara Penentuan Estimasi Ketidakpastian Pengukuran. Pelatihan Sampling dan Preparasi Sampel Lingkungan untuk Analisis Unsur Kelumit. Di PTAPB BATAN, PUSTIKALAT BATAN Jakarta (2007).

6. ANONIM., "SERTIFIKAT KALIBRASI" No Order : 0018/VII/ORD/ILS/05, Timbangan Elektronik tipe AP 2500. Laboratorium Kalibrasi Divisi Teknik, Indocal Laboratorium Sistem. Bandung (2005).

7. ANONIM., Standard Reference Material (SRM) with Buffalo River Sediment 2704. Gaithersbuurg, MD 20899.

8. SUKIRNO., TAFTAZANI.A., SUMINING., "Evaluasi Presisi dan Akurasi Hasil Analisis Fe, Ti dan Ce dengan Metoda XRF", Prosiding Seminar Nasional VI., Kimia dalam Lingkungan, Jasakiai, Jogjakarta (2003)

9. DAY,Jr. dan UNDERWOOD. A.L., Analisis Kimia Kuantitatif. Edisi Kelima., Erlangga, Jakarta (1986) 